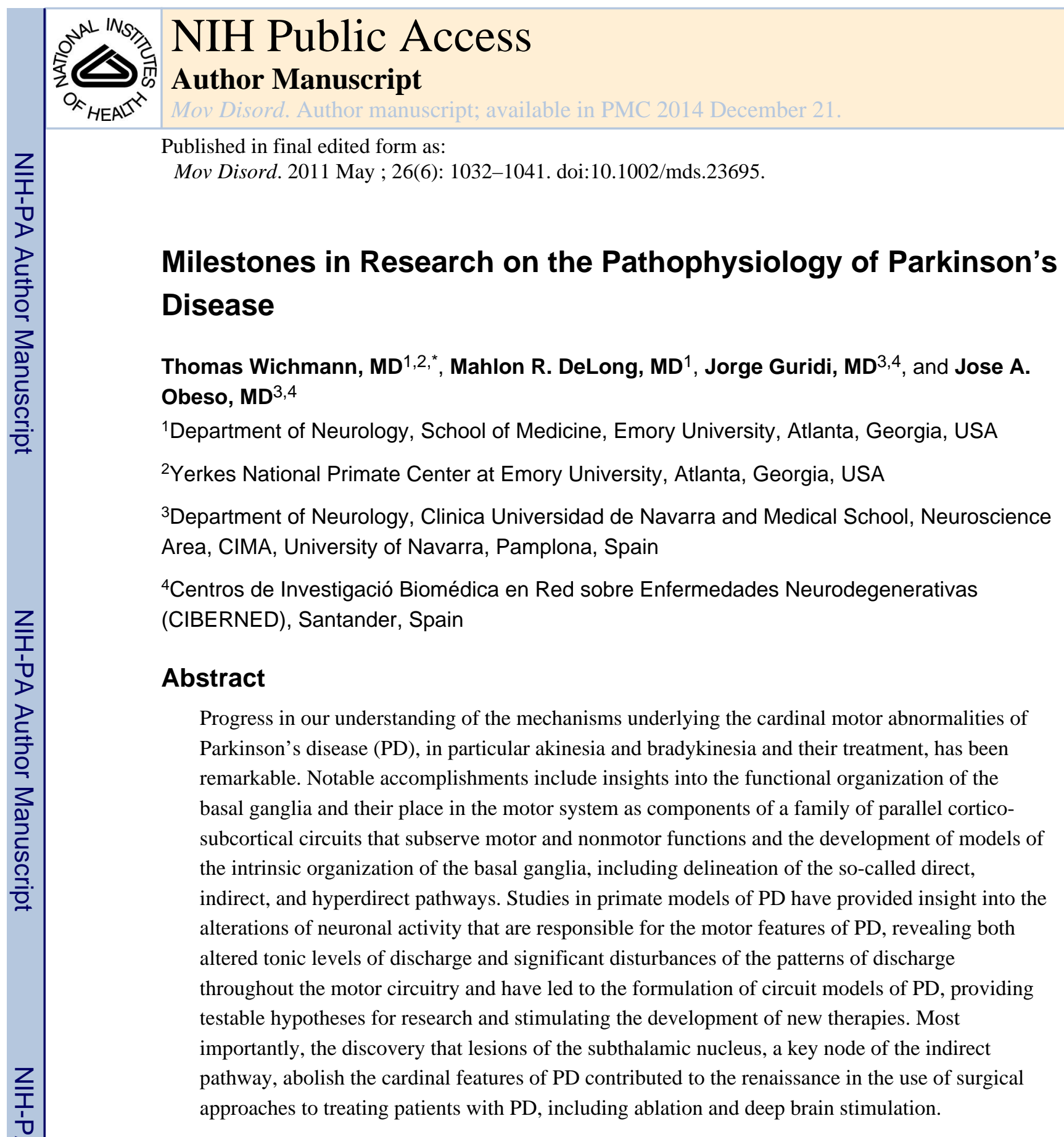

\title{
Keywords
}

basal ganglia; direct pathway; indirect pathway; dyskinesias; deep brain stimulation; pallidotomy

Over the past decades, there has been considerable progress in our understanding of the pathophysiology of Parkinson's disease (PD). The refinement of pathophysiologic circuit

(C) 2011 Movement Disorder Society

*Correspondence to: Dr. Thomas Wichmann, Yerkes National Primate Center, Division of Neuropharmacology and Neurologic Diseases, 954 Gatewood Road, Atlanta, GA 30322, USA; twichma@emory.edu.

Relevant conflicts of interest/financial disclosures: Nothing to report. Full financial disclosures and author roles may be found in the online version of this article. 
models has provided testable hypotheses for research and stimulated the search for new therapies. In this article, we will highlight major milestones of discovery in this process.

The term pathophysiology will be used in a restricted sense, to refer to the anatomic localization and physiologic changes in neuronal activity in the basal ganglia and related structures that occur in response to the dopamine loss seen in PD. Dopamine loss is thought to result in the motor aspects of the disorder, in particular, the cardinal features of bradykinesia and akinesia. Although PD encompasses a spectrum of other motor and nonmotor manifestations that are largely nondopaminergic in origin, ${ }^{1-6}$ our understanding of the pathophysiologic origin of these alterations remains very limited and will not be discussed.

\section{Models of Basal Ganglia Circuitry}

The development of a better understanding of the functional organization of the basal ganglia was highly important in the quest for testable pathophysiological models. In this section we briefly review these important insights into the anatomy and function of the basal ganglia and associated areas in the thalamus and cortex. In subsequent sections, the pathophysiologic significance of this knowledge will be elaborated. A major step in this direction was the insight that the portions of the basal ganglia that are involved in movement are separate from the nonmotor areas and that basal ganglia circuits are (largely) separate from those of the cerebellum. Building on electrophysiologic studies in the primate, which revealed a somatotopic organization of basal ganglia neurons related to movement of individual body parts and highly specific relations to aspects of movement, ${ }^{7}$ and on a review of the available anatomic data, a model was proposed in the mid-1980s in which the basal ganglia are viewed as components of segregated circuits that subserve different functions, determined by the functional role of the respective cortical area of origin of the different circuits. ${ }^{8}$ This "parallel-circuit" hypothesis (Fig. 1) identified discrete cortico-basal gangliathalamocortical circuits, subserving skeletomotor, oculomotor, associative (executive), and limbic functions. Although at the time it was believed that the motor circuit targeted only the supplementary motor area (as shown in Fig. 1, a reproduction of a figure from the original article), it is now clear that the motor circuit is, in fact, comprised of subcircuits centered on different precentral motor fields. ${ }^{9-13}$ It is accepted that the parallel- circuit hypothesis offers an anatomical explanation for the common development of behavioral, cognitive, and limbic features in basal ganglia disorders and for the prominence of motor features in the clinical presentation of PD because the earliest and most extensive loss of dopamine in the striatum occurs in the postcommissural putamen, ${ }^{14,15}$ the striatal portion of the motor circuit.

In addition to the overall circuit organization, the intrinsic connections of the basal ganglia were elucidated in the 1980s and early 1990s, with the formulation of the model of "direct" and "indirect" striatal output pathways, ${ }^{16-18}$ by which the striatum, the principal basal ganglia input structure, is linked to the basal ganglia output structures, that is, the internal pallidal segment (GPi) and the substantia nigra pars reticulata ( $\mathrm{SNr}$ ). The direct and indirect pathways were shown to originate from separate populations of striatal medium spiny neurons (MSNs) whose activity is differentially modulated by dopamine. ${ }^{19}$ The direct pathway is a monosynaptic inhibitory projection between MSNs that contain substance-P 
and dopamine D1-receptors, and GPi/SNr neurons. The indirect pathway is a polysynaptic connection that involves an inhibitory projection from MSNs that express dopamine D2receptors and enkephalin to the neurons in the external pallidal segment (GPe), and subsequent inhibitory projections between GPe and GPi/SNr, either directly or via the intercalated glutamatergic subthalamic nucleus (STN; Fig. 2A, reproduced from the original figure in Bergman et $\mathrm{al}^{20}$ ).

The anatomical presence of direct and indirect pathways has been hypothesized to have substantial functional consequences. Activation of MSNs that give rise to the direct pathway would result in the inhibition of GPi and SNr neurons that, in turn, may lead to reduced inhibition of thalamocortical projection neurons and thus to facilitation of movement. Because of the polarities of the connections involved, activation of the indirect pathway would have the opposite effect, that is, an increase of basal ganglia output and suppression of movement. ${ }^{16-18}$

Another anatomical pathway that may have a substantial role in the control of basal ganglia output is the so-called hyperdirect pathway, which includes a cortico-subthalamic connection. ${ }^{21-23}$ Activation of this pathway would also act to increase basal ganglia output, resulting in greater inhibition of thalamocortical activities. Although these actions are similar in polarity to those of the indirect pathway, they are considered to be much faster than those mediated by the indirect pathway because they circumvent the relatively slow processing in the striatum and GPe.

With the introduction of transgenic animals in which the direct and indirect pathways can be visualized in brain slice recording studies, a large number of functional differences between the MSNs that give rise to these pathways have been found, ${ }^{24-29}$ which may explain their respective involvement in the normal functions of the basal ganglia and in some aspects of the pathophysiology of parkinsonism. In vivo evidence for such differences is largely lacking at this time but should be forthcoming with the help of novel optogenetic and other techniques (see, eg, Kravitz et al ${ }^{30}$ ).

\section{The Rate Model of Parkinsonism}

In the 1960s it had been established that the striatal dopamine content was decreased in patients with PD and that the cardinal features of the disorder could be reversed with administration of levodopa, a precursor of dopamine. ${ }^{15,31-33}$ The subsequent development of pathophysiologic models of PD benefited greatly from animal models of dopamine depletion. Among these, the model created by treating primates with the dopaminergic neurotoxin 1-methyl-4-phenyl-1,2,3,6-tetrahydropyridine (MPTP) has had the greatest impact. ${ }^{34-36}$

An important insight gained from studies in such animals was the demonstration of changes in the uptake of 2-deoxyglucose (2DG) in individual basal ganglia nuclei, which mainly reflects the amount of afferent activities in a given area. Studies by Alan Crossman and colleagues showed that 2DG uptake was increased in the GPe, GPi, and ventral anterior and ventral lateral thalamic nuclei ${ }^{37-40}$ and was reduced in the STN. ${ }^{39,40}$ Subsequent electrophysiological recordings of neuronal activity in MPTP-treated primates confirmed 
that the spontaneous neuronal activity in the STN and GPi are increased, whereas that in the GPe is decreased. ${ }^{41-43}$ Together, these metabolic and electrophysiologic data suggested that the MSNs that give rise to the indirect pathway are overactive, leading to inhibition of GPe neurons, which, in turn, results in disinhibition of the STN and excessive excitation of the GPi. The resulting increased basal ganglia output to the thalamus was thought to then excessively inhibit thalamic neurons projecting to the cerebral cortex.

In contrast to this model of PD, in which increased basal ganglia output led to a reduction of movement, studies of changes in metabolism or electrophysiologic activity found reduced basal ganglia output in animal models of hyperkinetic states, such as experimentally induced chorea, hemiballism, and levodopa-induced dyskinesias in monkeys. ${ }^{44-49}$ Both lines of evidence led to the development of new concepts about the pathophysiology of PD, strongly linked to the proposed organization of these structures into direct and indirect pathways. These pathophysiologic models were summarized in two landmark review articles, by Albin, Penney, and Young ${ }^{17}$ in 1989 and by DeLong in 1990, ${ }^{18}$ which described the global activity changes of basal ganglia nuclei in movement disorders. In these articles and subsequent reviews on this topic (eg, Obeso et al ${ }^{50}$ ), striatal dopamine depletion was postulated to result in increased inhibitory activity over the indirect pathway and decreased activity over the direct pathway, leading to increased inhibitory output from the GPi to the thalamus. In contrast, hyperkinetic disorders such as hemiballismus, chorea, and druginduced dyskinesias were postulated to result from decreased GPi output (Fig. 2B). The development of these models greatly stimulated further investigations into the pathophysiology of PD.

The proposed role of increased activity in the STN and GPi in parkinsonism was strongly supported by positron emission tomography (PET) studies ${ }^{51}$ and by experiments showing that lesions of the STN in MPTP-treated primates almost instantaneously and substantially ameliorate the cardinal motor signs of parkinsonism ${ }^{20,52-54}$ (Fig. 2C) and reduce activity in the basal ganglia output nuclei toward more normal levels. ${ }^{52,54}$ These lesion studies helped to rekindle the interest of neurosurgeons and neurologists in lesioning approaches for patients with advanced PD, which had largely lain dormant since the introduction of levodopa treatment for PD. ${ }^{55-60}$ This first resulted in the reintroduction of GPi pallidotomy, which had clinical effects similar to STN lesions in primates. Lesioning of the STN has also been used as a treatment in patients with PD. Interestingly, such lesions are well tolerated and are not, as initially feared, associated with severe hemiballism in most cases. ${ }^{60}$

Soon after the reintroduction of ablative treatments for PD, the first trials of chronic highfrequency electrical stimulation (deep brain stimulation [DBS]) of basal ganglia targets were carried out in parkinsonian patients. DBS had been employed earlier for movement disorders in the thalamus for treatment of tremor. ${ }^{61,62}$ Based on the notion that chronic high-frequency stimulation may have inhibitory effects on the stimulated brain area and a study demonstrating therapeutic effects of high-frequency stimulation of the STN in MPTP-treated monkeys, ${ }^{63}$ a group led by Benabid and Pollak carried out a trial of STN-DBS in PD patients. ${ }^{64}$ This study and a large body of literature published since then demonstrated substantial and sustained benefits of DBS that are very similar to those obtained by lesioning the STN. ${ }^{58-60}$ Because DBS has the advantage of being reversible and adjustable, this 
technique has now largely replaced ablative surgery for patients with advanced PD in many parts of the world. ${ }^{65-67}$

\section{Pattern Abnormalities and Neuronal Synchrony}

Soon after the formulation of the rate model, the researchers started to identify significant inconsistencies with this model, in particular, that lesions of the motor thalamus do not result in akinesia and that lesions of the GPi do not result in dyskinesias. ${ }^{50,68-70}$ This realization shifted the attention of researchers to disturbances of neuronal activity in the basal ganglia other than changes in the spontaneous frequency of discharge. In fact, even the earliest studies of basal ganglia dysfunction in MPTP-treated animals had shown that basal ganglia neurons in the parkinsonian state exhibit prominent alterations of their discharge patterns. ${ }^{41,43,71}$ Some of these changes are exemplified in the single-cell recordings from parkinsonian primates in Figure 3. One of the principal changes is a greater tendency of neurons in the GPe, STN, GPi, SNr, and basal ganglia-receiving areas of the thalamus to discharge in bursts. ${ }^{72}$ The physiological mechanisms underlying this phenomenon are not clear, but rebound burst generation, that is, the transient production of excessive spiking activity following a period of strong inhibition, is likely to play a significant role and has been demonstrated to occur in GPe, GPi, STN, and thalamic neurons. ${ }^{73-77}$

Another prominent change in neuronal activity is that the discharge of basal ganglia neurons becomes more synchronous in the parkinsonian state. Under normal conditions, most neurons in these nuclei discharge independently, but in parkinsonian animals and in human patients with PD, neuronal synchrony is frequently observed in both the basal ganglia and the cortex..$^{71,78-84}$ In a sense, dopamine appears to act to maintain the segregation of neuronal activities, which then breaks down in its absence.

In addition, neurons in the basal ganglia, thalamus, and cortex also develop abnormal oscillatory firing patterns, particularly in the alpha- and beta-range of frequencies (eg, Bergman et al,${ }^{71}$ Gatev et al,${ }^{85}$ and Rivlin-Etzion et al ${ }^{86}$ ). The idea that oscillatory bursts and the synchrony of basal ganglia activities may be important in the pathophysiology of parkinsonism was further developed in the early 2000s, when Brown and colleagues reported that local field potentials (LFPs), recorded from implanted DBS macro-electrodes in the STN of PD patients, indicated synchronized oscillatory activities of large populations of neural elements in and around this structure. ${ }^{87}$ Abnormal beta-frequency oscillations can be detected in recordings from unmedicated parkinsonian patients. The oscillations are reduced by levodopa treatment, whereas gamma-band oscillations are increased ${ }^{87}$ (Fig. 4). Subsequent studies have documented that similar oscillations also occur in the GPi and cortex of PD patients. Together with the previous single-cell recordings studies, these findings suggested that the basal ganglia-thalamocortical circuitry may be engaged in hypersynchronized pathological oscillations that disturb normal movement-related activities in PD. ${ }^{88,89}$ Since the original description by Brown and colleagues, other studies have shown that abnormal oscillatory activity and synchronization of the basal ganglia do not only characterize the parkinsonian state but are also found (at different frequencies) in association with levodopa-induced dyskinesias (Fig. 4) ${ }^{90}$ and impulse control disorders in PD. ${ }^{91}$ It needs to be mentioned, however, that although hypersynchronized oscillatory 
activities occur in PD, it is not (yet) established that they are necessary and sufficient to produce parkinsonism. Thus, studies in MPTP-treated monkeys have suggested that such activities may occur relatively late in the process of developing parkinsonism (or may not develop at all, despite the presence of parkinsonian signs, according to unpublished data and Leblois et $\mathrm{al}^{92}$ ). Acute dopamine depletion in rats has also been shown to result in disturbances of motor function without the development of abnormal oscillatory activities. ${ }^{93}$

It is worth noting that in both the "rate" model and in the newer models based on firing pattern abnormalities, activity changes in the indirect pathway are specifically implicated in the development of the major motor features of PD. The importance of indirect pathway dysfunction is further supported by the finding that STN lesions or DBS successfully ameliorates parkinsonian motor features. Recent studies in mice using optogenetic techniques have also demonstrated that activation of indirect-pathway MSNs results in bradykinesia and reduced locomotion in otherwise normal animals, whereas activation of direct-pathway neurons reduces freezing and increases locomotion in animal models of PD. ${ }^{30}$

\section{Akinesia as a Disorder of "Focusing"}

The idea that activation of the direct pathway is mainly responsible for movement facilitation whereas activation of the indirect pathway suppresses movement and that disturbances of the balance between these functions contribute to the pathophysiology of PD and other movement disorders is an essential part of the aforementioned rate model, and, as described above, became established as a fundamental scheme of the physiologic functions of the basal ganglia. ${ }^{18,94,95}$ The functional implications of the direct/indirect pathway model were further elaborated by Mink and Thach, who proposed that the basal ganglia may act to "focus" movements through the interplay of the facilitatory actions of the direct pathway and the suppressive actions of the indirect and hyperdirect pathways. ${ }^{22,96,97}$ This model is also championed by studies by Nambu et al., based on studies of the effects of electrical motor cortex stimulation on basal ganglia activities in monkeys. ${ }^{22,97,98}$ Akinesia could then be understood as a dopamine-depletion-induced imbalance of the two main striatopallidal systems, in which overly restrictive focusing via the indirect pathway leads to suppression of intended movements. ${ }^{99}$ Although this focusing model of basal ganglia function and dysfunction has gained considerable attention, it remains controversial. The fact that GPi lesions in primates and posteroventral pallidotomy in PD patients are not associated with obvious deleterious effects on movement or posture, and the well-documented late onset of GPi discharge in relation to movement onset, are major inconsistencies of this hypothesis.

\section{Parkinsonism Interpreted as Disorder of Basal Ganglia Interference with Cortical Functions}

Soon after the initial publication of the rate model, Marsden and Obeso discussed that the model was at odds with the finding that lesions of the motor thalamus do not cause or worsen akinesia. ${ }^{70}$ These observations suggested that the basal ganglia may not directly facilitate or inhibit movement, but may aid cortical operations more subtly in the acquisition and execution of automatic movements and the adjustment of behavior to the occurrence of 
unexpected events. The abnormal activity of the basal ganglia in PD may simply interfere with cortical operations. Surgical disruption of the basal ganglia-thalamocortical connections by lesioning or DBS would free cortical operations from subcortical "noise." Of course, surgical elimination of basal ganglia output would also be expected to eliminate the contribution of the basal ganglia-thalamocortical system to normal behavior, potentially resulting in deficits in motor learning and an inability of directing actions to novel events. In fact, recent studies have documented that patients with PD preferentially lose functions of the dorsolateral striatum, including specifically the learning and execution of habits and procedures (reviewed in Redgrave et $\mathrm{al}^{100}$ ) and that PD patients with therapeutic nearcomplete lesions of the basal ganglia motor output through combined pallidotomy/ subthalamotomy procedures ${ }^{101,102}$ show further reductions in implicit learning.

\section{Other Aspects of PD Pathophysiology}

The loss of dopamine not only influences the functional balance between direct, indirect, and hyperdirect pathways and spontaneous firing patterns of the basal ganglia, but also affects the anatomical integrity of striatal (and probably other basal ganglia) cells. Thus, studies in animal models of dopamine loss and in patients with PD have demonstrated a loss of dendritic spines on striatal MSNs. ${ }^{103-109}$ In rodent preparations, this anatomical change may particularly affect MSNs that give rise to the indirect pathway, ${ }^{108}$ but in MPTP-treated monkeys the process of spine elimination appears to be less specific. ${ }^{103}$ Spine loss may have significant consequences on synaptic plasticity and adaptive changes in the striatum and may contribute to the aforementioned learning deficits in PD patients (also see above). In addition to the neuronal degeneration in the substantia nigra pars compacta, cell loss has also been documented to occur in other brain areas, such as the intralaminar nuclei of the thalamus, both in patients with PD and in animal models of dopamine depletion. ${ }^{110,111}$ The functional significance of these changes and their apparent link to the dopamine cell loss remain unclear.

In recent years it has also been recognized that dopamine loss outside the striatum may be involved in the pathophysiology of parkinsonism. Rodent and monkey studies have suggested that dopamine has substantial effects on neuronal firing in the GPe, GPi, and SNr, and perhaps also in the STN (reviewed in Rommelfanger et al ${ }^{112}$ ). The dopamine concentrations at these locations is much smaller than that in the striatum, ${ }^{113}$ so that the ultimate effect of the loss of endogenous dopamine in these areas is not clear. However, dopamine receptor activation by dopaminergic therapies in parkinsonism is likely to have strong effects in these areas and may contribute to the antiparkinsonian and adverse effects of these agents.

\section{Conclusions}

Our knowledge of changes in brain activity that develop as a consequence of dopamine loss has greatly expanded over the last decades, although we are far from a comprehensive mechanistic understanding of the pathophysiology of PD. However, the development of the models mentioned above has significantly altered our approach to treating parkinsonian patients. Thus, the models have helped with the development of some of the currently used 
medication treatments and are being used to develop new ones, aimed at amplifying or modulating the responses to dopaminergic treatments (for instance, adenosinergic drugs or metabotropic glutamate receptor agents). Perhaps the most significant impact of these studies and models has been that they helped to revive interest in neurosurgical treatments and guided targeting of surgical approaches to the motor portions of the basal ganglia and thalamus, leading to more effective treatment of tens of thousands of patients with advanced PD.

In the future, other basic issues need to be addressed, including questions about the relevance of the loss of dopamine for cognitive and executive function, mood regulation, and learning (eg, Knowlton et a ${ }^{114}$ ) and the origin of motor manifestations that are not sensitive to dopaminergic and surgical treatments. It is hoped that the application of novel experimental approaches, such as optogenetic techniques, which are able to dissect with greater specificity the activity and role of specific neuronal components of the larger circuits, will address these and other issues. ${ }^{30}$

\section{Acknowledgments}

Writing this article was supported in part by NIH/NINDS grants R01NS054976 and P50NS071669 (to T.W.) and an infrastructure grant to the Yerkes National Primate Research Center (NIH/NCRR grant RR-000165).

\section{References}

1. Braak H, Del Tredici K, Bratzke H, Hamm-Clement J, Sandmann-Keil D, Rub U. Staging of the intracerebral inclusion body pathology associated with idiopathic Parkinson's disease (preclinical and clinical stages). J Neurol. 2002; 249(Suppl 3):III/1-III/5.

2. Burke RE, Dauer WT, Vonsattel JP. A critical evaluation of the Braak staging scheme for Parkinson's disease. Ann Neurol. 2008; 64:485-491. [PubMed: 19067353]

3. Del Tredici K, Rub U, De Vos RA, Bohl JR, Braak H. Where does parkinson disease pathology begin in the brain? J Neuropathol Exp Neurol. 2002; 61:413-426. [PubMed: 12030260]

4. Dickson DW, Uchikado H, Fujishiro H, Tsuboi Y. Evidence in favor of Braak staging of Parkinson's disease. Mov Disord. 2010; 25(Suppl 1):S78-S82. [PubMed: 20187227]

5. Hawkes CH, Del Tredici K, Braak H. A timeline for Parkinson's disease. Parkinsonism Relat Disord. 2010; 16:79-84. [PubMed: 19846332]

6. Jellinger KA. Critical evaluation of the Braak staging scheme for Parkinson's disease. Ann Neurol. 2010; 67:550. [PubMed: 20437592]

7. DeLong, MR.; Georgopoulos, AP. Motor functions of the basal ganglia. In: Brookhart, JM.; Mountcastle, VB.; Brooks, VB.; Geiger, SR., editors. Handbook of Physiology The Nervous System Motor Control. Section 1, Vol. II, Part 2. Bethesda, MD: American Physiological Society; 1981. p. 1017-1061.

8. Alexander GE, DeLong MR, Strick PL. Parallel organization of functionally segregated circuits linking basal ganglia and cortex. Annu Rev Neurosci. 1986; 9:357-381. [PubMed: 3085570]

9. Kelly RM, Strick PL. Macro-architecture of basal ganglia loops with the cerebral cortex: use of rabies virus to reveal multisynaptic circuits. Prog Brain Res. 2004; 143:449-459. [PubMed: 14653187]

10. Bergman H, Feingold A, Nini A, et al. Physiological aspects of information processing in the basal ganglia of normal and parkinsonian primates. Trends Neurosci. 1998; 21:32-38. [PubMed: 9464684]

11. Turner RS, Grafton ST, Votaw JR, Delong MR, Hoffman JM. Motor subcircuits mediating the control of movement velocity: a PET study. J Neurophysiol. 1998; 80:2162-2176. [PubMed: 9772269] 
12. Hoover JE, Strick PL. Multiple output channels in the basal ganglia. Science. 1993; 259:819-821. [PubMed: 7679223]

13. Middleton FA, Strick PL. Basal ganglia and cerebellar loops: motor and cognitive circuits. Brain Res Rev. 2000; 31:236-250. [PubMed: 10719151]

14. Ehringer H, Hornykiewicz O. Verteilung von Noradrenalin und Dopamin (3-Hydroxytyramin) im Gehirn des Menschen und ihr Verhalten bei Erkrankungen des extrapyramidalen Systems. KlinWschr. 1960; 38:1236-1239.

15. Bernheimer H, Birkmayer W, Hornykiewicz O, Jellinger K, Seitelberger F. Brain. dopamine and the syndromes of Parkinson and Huntington. J Neurol Sci. 1973; 20:415-455. [PubMed: 4272516]

16. Penney JB Jr, Young AB. Striatal inhomogeneities and basal ganglia function. Mov Disord. 1986; 1:3-15. [PubMed: 2848190]

17. Albin RL, Young AB, Penney JB. The functional anatomy of basal ganglia disorders. Trends Neurosci. 1989; 12:366-375. [PubMed: 2479133]

18. DeLong MR. Primate models of movement disorders of basal ganglia origin. Trends Neurosci. 1990; 13:281-285. [PubMed: 1695404]

19. Gerfen CR, Engber TM, Mahan LC, et al. D1 and D2 dopamine receptor-regulated gene expression of striatonigral and striatopallidal neurons. Science. 1990; 250:1429-1432. [PubMed: 2147780]

20. Bergman H, Wichmann T, DeLong MR. Reversal of experimental parkinsonism by lesions of the subthalamic nucleus. Science. 1990; 249:1436-1438. [PubMed: 2402638]

21. Hartmann-von Monakow K, Akert K, Kunzle H. Projections of the precentral motor cortex and other cortical areas of the frontal lobe to the subthalamic nucleus in the monkey. Exp Brain Res. 1978; 33:395-403. [PubMed: 83239]

22. Nambu A, Tokuno H, Hamada I, et al. Excitatory cortical inputs to pallidal neurons via the subthalamic nucleus in the monkey. J Neurophysiol. 2000; 84:289-300. [PubMed: 10899204]

23. Tokuno H, Nambu A. Organization of nonprimary motor cortical inputs on pyramidal and nonpyramidal tract neurons of primary motor cortex: An electrophysiological study in the macaque monkey. Cerebr Cortex. 2000; 10:58-68.

24. Gertler TS, Chan CS, Surmeier DJ. Dichotomous anatomical properties of adult striatal medium spiny neurons. J Neurosci. 2008; 28:10814-10824. [PubMed: 18945889]

25. Taverna S, Ilijic E, Surmeier DJ. Recurrent collateral connections of striatal medium spiny neurons are disrupted in models of Parkinson's disease. J Neurosci. 2008; 28:5504-5512. [PubMed: 18495884]

26. Kreitzer AC, Malenka RC. Endocannabinoid-mediated rescue of striatal LTD and motor deficits in Parkinson's disease models. Nature. 2007; 445:643-647. [PubMed: 17287809]

27. Day M, Wokosin D, Plotkin JL, Tian X, Surmeier DJ. Differential excitability and modulation of striatal medium spiny neuron dendrites. J Neurosci. 2008; 28:11603-11614. [PubMed: 18987196]

28. Bateup HS, Santini E, Shen W, et al. Distinct subclasses of medium spiny neurons differentially regulate striatal motor behaviors. Proc Natl Acad Sci U S A. 2010; 107:14845-14850. [PubMed: 20682746]

29. Tian X, Kai L, Hockberger PE, Wokosin DL, Surmeier DJ. MEF-2 regulates activity-dependent spine loss in striatopallidal medium spiny neurons. Mol Cell Neurosci. 2010; 44:94-108. [PubMed: 20197093]

30. Kravitz AV, Freeze BS, Parker PR, et al. Regulation of parkinsonian motor behaviours by optogenetic control of basal ganglia circuitry. Nature. 2010; 466:622-626. [PubMed: 20613723]

31. Birkmayer W, Hornykiewicz O. Der L-3dioxphenylalanin (DOPA)-Effekt bei der ParkinsonAkinese. Wien Klin Wochenschr. 1961; 73:787-788. [PubMed: 13869404]

32. Carlsson A. Biochemical and pharmacological aspects of Parkinsonism. Acta Neurol Scand Suppl. 1972; 51:11-42. [PubMed: 4351191]

33. Yahr MD, Duvoisin RC. Drug therapy of parkinsonism. N Engl J Med. 1972; 287:20-24. [PubMed: 4555145]

34. Davis GC, Williams AC, Markey SP, et al. Chronic parkinsonism secondary to intravenous injection of meperidine analogues. Psychiatry Res. 1979; 1:249-254. [PubMed: 298352] 
35. Langston JW, Ballard P, Tetrud JW, Irwin I. Chronic Parkinsonism in humans due to a product of meperidine-analog synthesis. Science. 1983; 219:979-980. [PubMed: 6823561]

36. Burns RS, Chiueh CC, Markey SP, Ebert MH, Jacobowitz DM, Kopin IJ. A primate model of parkinsonism: selective destruction of dopaminergic neurons in the pars compacta of the substantia nigra by N-methyl-4-phenyl-1,2,3,6-tetrahydropyridine. Proc Natl Acad Sci U S A. 1983; 80:4546-4550. [PubMed: 6192438]

37. Crossman AR, Mitchell IJ, Sambrook MA. Regional brain uptake of 2-deoxyglucose in Nmethyl-4-phenyl-1,2,3,6-tetrahydropyridine (MPTP)-induced parkinsonism in the macaque monkey. Neuropharmacology. 1985; 24:587-591. [PubMed: 3875056]

38. Mitchell IJ, Cross AJ, Sambrook MA, Crossman AR. Neural mechanisms mediating 1-methyl-4phenyl-1,2,3, 6-tetrahydropyridine-induced parkinsonism in the monkey: relative contributions of the striatopallidal and striatonigral pathways as suggested by 2-deoxyglucose uptake. Neurosci Lett. 1986; 63:61-65. [PubMed: 3485267]

39. Schwartzman RJ, Alexander GM. Changes in the local cerebral metabolic rate for glucose in the 1methyl-4-phenyl-1,2,3,6-tetrahydropyridine (MPTP) primate model of Parkinson's disease. Brain Res. 1985; 358:137-143. [PubMed: 3878182]

40. Schwartzman RJ, Alexander GM. Changes in the local cerebral metabolic rate for glucose in the MPTP primate model of Parkinson's disease. Adv Neurol. 1987; 45:171-173. [PubMed: 3493624]

41. Miller, WC.; DeLong, MR. Altered tonic activity of neurons in the globus pallidus and subthalamic nucleus in the primate MPTP model of parkinsonism. In: Carpenter, MB.; Jayaraman, A., editors. The Basal Ganglia II. New York: Plenum Press; 1987. p. 415-427.

42. Filion, M.; Tremblay, L.; Bedard, PJ. Excessive and Unselective Responses of Medial Pallidal Neurons to Both Passive Movements and Striatal Stitmulation in Monkeys with MPTP-Induced Parkinsonism. London: John Libbey; 1989.

43. Filion M, Tremblay L. Abnormal spontaneous activity of globus pallidus neurons in monkeys with MPTP-induced parkinsonism. Brain Res. 1991; 547:142-151. [PubMed: 1677607]

44. Crossman AR. A hypothesis on the pathophysiological mechanisms that underlie levodopa- or dopamine agonist-induced dyskinesia in Parkinson's disease: implications for future strategies in treatment. Mov Disord. 1990; 5:100-108. [PubMed: 1970120]

45. Mitchell IJ, Sambrook MA, Crossman AR. Subcortical changes in the regional uptake of [3H]-2deoxyglucose in the brain of the monkey during experimental choreiform dyskinesia elicited by injection of a gamma-aminobutyric acid antagonist into the subthalamic nucleus. Brain. 1985; 108:405-422. [PubMed: 4005529]

46. Mitchell IJ, Jackson A, Sambrook MA, Crossman AR. Common neural mechanisms in experimental chorea and hemiballismus in the monkey. Evidence from 2-deoxyglucose autoradiography. Brain Res. 1985; 339:346-350. [PubMed: 4027631]

47. Crossman AR, Mitchell IJ, Sambrook MA, Jackson A. Chorea and myoclonus in the monkey induced by gamma-aminobutyric acid antagonism in the lentiform complex. The site of drug action and a hypothesis for the neural mechanisms of chorea. Brain. 1988; 111:1211-1233. [PubMed: 3179691]

48. Hamada I, DeLong MR. Excitotoxic acid lesions of the primate subthalamic nucleus result in reduced pallidal neuronal activity during active holding. J Neurophysiol. 1992; 68:1859-1866. [PubMed: 1479449]

49. Hamada I, DeLong MR. Excitotoxic acid lesions of the primate subthalamic nucleus result in transient dyskinesias of the contralateral limbs. J Neurophysiol. 1992; 68:1850-1858. [PubMed: 1479448]

50. Obeso JA, Rodriguez MC, DeLong MR. Basal ganglia pathophysiology. A critical review. Adv Neurol. 1997; 74:3-18. [PubMed: 9348398]

51. Ceballos-Bauman AO, Obeso JA, Vitek JL, et al. Restoration of thalamocortical activity after posteroventrolateral pallidotomy in Parkinson's disease. Lancet. 1994; 344:814. [PubMed: 7916090]

52. Wichmann T, Bergman H, DeLong MR. The primate subthalamic nucleus. III. Changes in motor behavior and neuronal activity in the internal pallidum induced by subthalamic inactivation in the MPTP model of parkinsonism. J Neurophysiol. 1994; 72:521-530. [PubMed: 7983516] 
53. Aziz TZ, Peggs D, Sambrook MA, Crossman AR. Lesion of the subthalamic nucleus for the alleviation of 1-methyl-4-phenyl-1,2,3,6-tetrahydropyridine (MPTP)-induced parkinsonism in the primate. Mov Disord. 1991; 6:288-292. [PubMed: 1758446]

54. Guridi J, Herrero MT, Luquin MR, et al. Subthalamotomy in parkinsonian monkeys. Behavioural and biochemical analysis. Brain. 1996; 119:1717-1727. [PubMed: 8931592]

55. Laitinen LV, Bergenheim AT, Hariz MI. Leksell's posteroventral pallidotomy in the treatment of Parkinson's disease. J Neurosurg. 1992; 76:53-61. [PubMed: 1727169]

56. Baron MS, Vitek JL, Bakay RA, et al. Treatment of advanced Parkinson's disease by posterior GPi pallidotomy: 1-year results of a pilot study. Ann Neurol. 1996; 40:355-366. [PubMed: 8797525]

57. Gill SS, Heywood P. Bilateral dorsolateral subthalamotomy for advanced Parkinson's disease. Lancet. 1997; 350:1224. [PubMed: 9652569]

58. Alvarez L, Macias R, Guridi J, et al. Dorsal subthalamotomy for Parkinson's disease. Mov Disord. 2001; 16:72-78. [PubMed: 11215596]

59. Alvarez L, Macias R, Lopez G, et al. Bilateral subthalamotomy in Parkinson's disease: initial and long-term response. Brain. 2005; 128:570-583. [PubMed: 15689366]

60. Alvarez L, Macias R, Pavon N, et al. Therapeutic efficacy of unilateral subthalamotomy in Parkinson's disease: results in 89 patients followed for up to 36 months. J Neurol Neurosurg Psychiatry. 2009; 80:979-985. [PubMed: 19204026]

61. Benabid AL, Pollak P, Louveau A, Henry S, Rougemont Jd. Combined (thalamotomy and stimulation) stereotactic surgery of the VIM thalamic nucleus for bilateral Parkinson disease. Appl Neurophysiol. 1987; 50:344-346. [PubMed: 3329873]

62. Benabid AL, Pollak P, Gervason C, et al. Long-term suppression of tremor by chronic stimulation of the ventral intermediate thalamic nucleus. Lancet. 1991; 337:403-406. [PubMed: 1671433]

63. Benazzouz A, Gross C, Feger J, Boraud T, Bioulac B. Reversal of rigidity and improvement in motor performance by subthalamic high-frequency stimulation in MPTP-treated monkeys. Eur J Neurosci. 1993; 5:382-389. [PubMed: 8261116]

64. Limousin P, Pollak P, Benazzouz A, et al. Bilateral subthalamic nucleus stimulation for severe Parkinson's disease. Mov Disord. 1995; 10:672-674. [PubMed: 8552123]

65. Rodriguez-Oroz MC, Obeso JA, Lang AE, et al. Bilateral deep brain stimulation in Parkinson's disease: a multicentre study with 4 years follow-up. Brain. 2005; 128:2240-2249. [PubMed: 15975946]

66. Rodriguez-Oroz MC, Gorospe A, Guridi J, et al. Bilateral deep brain stimulation of the subthalamic nucleus in Parkinson's disease. Neurology. 2000; 55:S45-S51. [PubMed: 11188975]

67. Weaver FM, Follett K, Stern M, et al. Bilateral deep brain stimulation vs best medical therapy for patients with advanced Parkinson disease: a randomized controlled trial. JAMA. 2009; 301:63-73. [PubMed: 19126811]

68. Brown P, Eusebio A. Paradoxes of functional neurosurgery: clues from basal ganglia recordings. Mov Disord. 2008; 23:12-20. quiz 158. [PubMed: 17999423]

69. DeLong MR, Wichmann T. Circuits and circuit disorders of the basal ganglia. Arch Neurol. 2007; 64:20-24. [PubMed: 17210805]

70. Marsden CD, Obeso JA. The functions of the basal ganglia and the paradox of stereotaxic surgery in Parkinson's disease. Brain. 1994; 117:877-897. [PubMed: 7922472]

71. Bergman H, Wichmann T, Karmon B, DeLong MR. The primate subthalamic nucleus. II. Neuronal activity in the MPTP model of parkinsonism. J Neurophysiol. 1994; 72:507-520. [PubMed: 7983515]

72. Wichmann T, Soares J. Neuronal firing before and after burst discharges in the monkey basal ganglia is predictably patterned in the normal state and altered in parkinsonism. J Neurophysiol. 2006; 95:2120-2133. [PubMed: 16371459]

73. Bevan MD, Wilson CJ, Bolam JP, Magill PJ. Equilibrium potential of GABA(A) current and implications for rebound burst firing in rat subthalamic neurons in vitro. J Neurophysiol. 2000; 83:3169-3172. [PubMed: 10805713]

74. Hallworth NE, Bevan MD. Globus pallidus neurons dynamically regulate the activity pattern of subthalamic nucleus neurons through the frequency-dependent activation of postsynaptic GABAA and GABAB receptors. J Neurosci. 2005; 25:6304-6315. [PubMed: 16000620] 
75. Bevan MD, Hallworth NE, Baufreton J. GABAergic control of the subthalamic nucleus. Prog Brain Res. 2007; 160:173-188. [PubMed: 17499114]

76. Nambu A, Llinas R. Electrophysiology of globus pallidus neurons in vitro. J Neurophysiol. 1994; 72:1127-1139. [PubMed: 7807199]

77. Cooper AJ, Stanford IM. Electrophysiological and morphological characteristics of three subtypes of rat globus pallidus neurone in vitro. J Physiol. 2000; 527:291-304. [PubMed: 10970430]

78. Levy R, Hutchison WD, Lozano AM, Dostrovsky JO. High-frequency synchronization of neuronal activity in the subthalamic nucleus of parkinsonian patients with limb tremor. J Neurosci. 2000; 20:7766-7775. [PubMed: 11027240]

79. Goldberg JA, Boraud T, Maraton S, Haber SN, Vaadia E, Bergman H. Enhanced synchrony among primary motor cortex neurons in the 1-methyl-4-phenyl-1,2,3,6-tetrahydropyridine primate model of Parkinson's disease. J Neurosci. 2002; 22:4639-4653. [PubMed: 12040070]

80. Uhlhaas PJ, Singer W. Neural synchrony in brain disorders: relevance for cognitive dysfunctions and pathophysiology. Neuron. 2006; 52:155-168. [PubMed: 17015233]

81. Raz A, Feingold A, Zelanskaya V, Vaadia E, Bergman H. Neuronal synchronization of tonically active neurons in the striatum of normal and parkinsonian primates. J Neurophysiol. 1996; 76:2083-2088. [PubMed: 8890317]

82. Raz A, Vaadia E, Bergman H. Firing patterns and correlations of spontaneous discharge of pallidal neurons in the normal and the tremulous 1-methyl-4-phenyl-1,2,3,6-tetrahydropyridine vervet model of parkinsonism. J Neurosci. 2000; 20:8559-8571. [PubMed: 11069964]

83. Cassidy M, Mazzone P, Oliviero A, et al. Movement-related changes in synchronization in the human basal ganglia. Brain. 2002; 125:1235-1246. [PubMed: 12023312]

84. Hammond C, Bergman H, Brown P. Pathological synchronization in Parkinson's disease: networks, models and treatments. Trends Neurosci. 2007; 30:357-364. [PubMed: 17532060]

85. Gatev P, Darbin O, Wichmann T. Oscillations in the basal ganglia under normal conditions and in movement disorders. Mov Disord. 2006; 21:1566-1577. [PubMed: 16830313]

86. Rivlin-Etzion M, Marmor O, Heimer G, Raz A, Nini A, Bergman H. Basal ganglia oscillations and pathophysiology of movement disorders. Curr Opin Neurobiol. 2006; 16:629-637. [PubMed: 17084615]

87. Brown P, Oliviero A, Mazzone P, Insola A, Tonali P, Di Lazzaro V. Dopamine dependency of oscillations between subthalamic nucleus and pallidum in Parkinson's disease. J Neurosci. 2001; 21:1033-1038. [PubMed: 11157088]

88. Brown P. Oscillatory nature of human basal ganglia activity: relationship to the pathophysiology of Parkinson's disease. Mov Disord. 2003; 18:357-363. [PubMed: 12671940]

89. Brown P. Abnormal oscillatory synchronisation in the motor system leads to impaired movement. Curr Opin Neurobiol. 2007; 17:656-664. [PubMed: 18221864]

90. Alonso-Frech F, Zamarbide I, Alegre M, et al. Slow oscillatory activity and levodopa-induced dyskinesias in Parkinson's disease. Brain. 2006; 129:1748-1757. [PubMed: 16684788]

91. Rodriguez-Oroz MC, Lopez-Azcarate J, Garcia-Garcia D, et al. Involvement of the subthalamic nucleus in impulse control disorders associated with Parkinson's disease. Brain. 2010

92. Leblois A, Meissner W, Bioulac B, Gross CE, Hansel D, Boraud T. Late emergence of synchronized oscillatory activity in the pallidum during progressive Parkinsonism. Eur J Neurosci. 2007; 26:1701-1713. [PubMed: 17880401]

93. Mallet N, Pogosyan A, Sharott A, et al. Disrupted dopamine transmission and the emergence of exaggerated beta oscillations in subthalamic nucleus and cerebral cortex. J Neurosci. 2008; 28:4795-4806. [PubMed: 18448656]

94. Chevalier G, Deniau JM. Disinhibition as a basic process in the expression of striatal functions. Trends Neurosci. 1990; 13:277-280. [PubMed: 1695403]

95. Alexander GE, Crutcher MD. Functional architecture of basal ganglia circuits: neural substrates of parallel processing. Trends Neurosci. 1990; 13:266-271. [PubMed: 1695401]

96. Mink JW, Thach WT. Basal ganglia intrinsic circuits and their role in behavior. Curr Opin Neurobiol. 1993; 3:950-957. [PubMed: 8124079] 
97. Nambu A. Seven problems on the basal ganglia. Curr Opin Neurobiol. 2008; 18:595-604. [PubMed: 19081243]

98. Nambu A, Tokuno H, Takada M. Functional significance of the cortico-subthalamo-pallidal 'hyperdirect' pathway. Neurosci Res. 2002; 43:111-117. [PubMed: 12067746]

99. Boraud T, Bezard E, Bioulac B, Gross CE. Ratio of inhibited-to-activated pallidal neurons decreases dramatically during passive limb movement in the MPTP-treated monkey. $\mathrm{J}$ Neurophysiol. 2000; 83:1760-1763. [PubMed: 10712496]

100. Redgrave P, Rodriguez M, Smith Y, et al. Goal-directed and habitual control in the basal ganglia: implications for Parkinson's disease. Nat Rev Neurosci. 2010; 11:760-772. [PubMed: 20944662]

101. Merello M, Balej J, Tenca E, Leiguarda R. Kinematic evaluation of gestural and repetitive single joint movements of the arm after posteroventral pallidotomy, subthalamotomy or both procedures combined in two Parkinson's disease patients: two case studies. Eur J Neurol. 2008; 15:406-412. [PubMed: 18353126]

102. Obeso JA, Jahanshahi M, Alvarez L, et al. What can man do without basal ganglia motor output? The effect of combined unilateral subthalamotomy and pallidotomy in a patient with Parkinson's disease. Exp Neurol. 2009; 220:283-292. [PubMed: 19744484]

103. Villalba RM, Lee H, Smith Y. Dopaminergic denervation and spine loss in the striatum of MPTPtreated monkeys. Exp Neurol. 2009; 215:220-227. [PubMed: 18977221]

104. Ingham CA, Hood SH, Arbuthnott GW. Spine density on neostriatal neurones changes with 6hydroxydopamine lesions and with age. Brain Res. 1989; 503:334-338. [PubMed: 2514009]

105. Ingham CA, Hood SH, Taggart P, Arbuthnott GW. Plasticity of synapses in the rat neostriatum after unilateral lesion of the nigrostriatal dopaminergic pathway. J Neurosci. 1998; 18:47324743. [PubMed: 9614247]

106. Ingham CA, Hood SH, van Maldegem B, Weenink A, Arbuthnott GW. Morphological changes in the rat neostriatum after unilateral 6-hydroxydopamine injections into the nigrostriatal pathway. Exp Brain Res. 1993; 93:17-27. [PubMed: 7682182]

107. Stephens B, Mueller AJ, Shering AF, et al. Evidence of a breakdown of corticostriatal connections in Parkinson's disease. Neuroscience. 2005; 132:741-754. [PubMed: 15837135]

108. Day M, Wang Z, Ding J, et al. Selective elimination of glutamatergic synapses on striatopallidal neurons in Parkinson disease models. Nat Neurosci. 2006; 9:251-259. [PubMed: 16415865]

109. Wang Z, Kai L, Day M, et al. Dopaminergic control of corticostriatal long-term synaptic depression in medium spiny neurons is mediated by cholinergic interneurons. Neuron. 2006; 50:443-452. [PubMed: 16675398]

110. Henderson JM, Carpenter K, Cartwright H, Halliday GM. Degeneration of the centre medianparafascicular complex in Parkinson's disease. Ann Neurol. 2000; 47:345-352. [PubMed: 10716254]

111. Aymerich MS, Barroso-Chinea P, Perez-Manso M, et al. Consequences of unilateral nigrostriatal denervation on the thalamostriatal pathway in rats. Eur J Neurosci. 2006; 23:2099-2108. [PubMed: 16630057]

112. Rommelfanger KS, Wichmann T. Extranigrostriatal dopaminergic circuits of the basal ganglia. Front Neuroanat. 2010; 4:139. [PubMed: 21103009]

113. Pifl C, Bertel O, G S, Hornykiewicz O. Extrastriatal dopamine in symptomatic and asymptomatic Rhesus monkeys treated with 1-methyl-4-phenyl-1,2,3,6-tetrahydropyridine (MPTP). Neurochem Int. 1990; 17:263-270. [PubMed: 20504626]

114. Knowlton BJ, Mangels JA, Squire LR. A neostriatal habit learning system in humans. Science. 1996; 273:1399-1402. [PubMed: 8703077]

115. Galvan A, Wichmann T. Pathophysiology of parkinsonism. Clin Neurophysiol. 2008; 119:14591474. [PubMed: 18467168] 


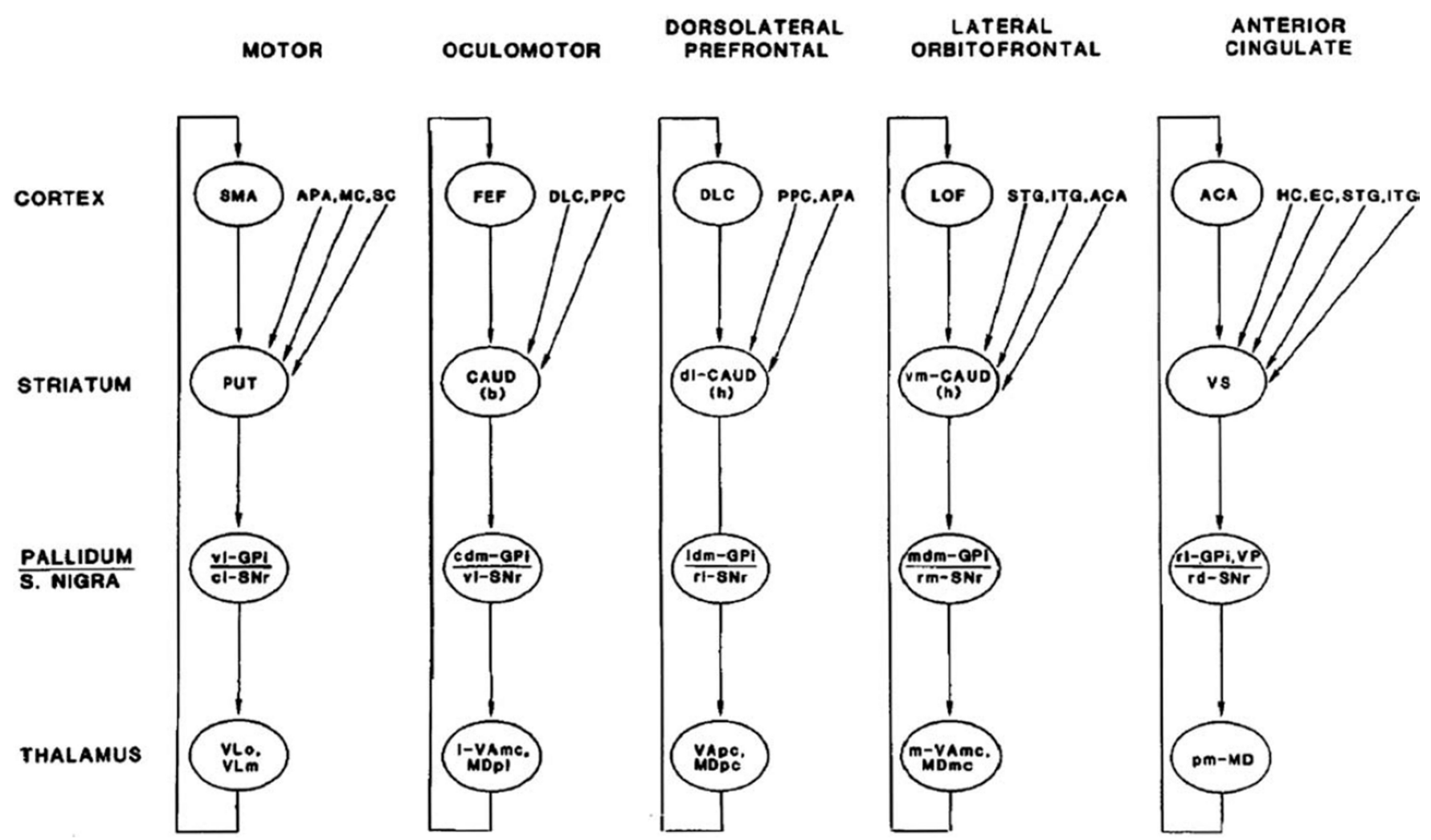

FIG. 1.

Basal ganglia-thalamocortical circuits as proposed by Alexander et al in $1986 .{ }^{8}$ See text for details. Abbreviations: ACA, anterior cingulate area; APA, arcuate premotor area; CAUD, caudate nucleus (b) body (h) head; DLC, dorsolateral prefrontal cortex; EC, entorhinal cortex; FEF, frontal eye fields; GPi, internal segment of globus pallidus; $\mathrm{HC}$, hippocampal cortex; ITG, inferior temporal gyrus; LOF, lateral orbitofrontal cortex; MC; motor cortex; $\mathrm{MDpl}$, medialis dorsalis pars paralamellaris; MDmc, medialis dorsalis pars magnocellularis; MDpc, medialis dorsalis pars parvocellularisl PPC, posterior parietal cortex; PUT, putamen; SC, somatosensory cortex; SMA, supplementary motor area; SNr, substantia nigra pars reticulata; STG, superior temporal gyrus; VAmc, ventralis anterior pars magnocellularis; VApc, ventralis anterior pars parvocellularis; VLm, ventralis lateralis pars medialis; VLo, ventralis lateralis pars oralis; VP, ventral pallidum; VS, ventral striatum; cl-, caudolateral; cdm-, cudal dorsomedial; dl-, dorsolateral; 1-, lateral; ldm-, lateral dorsomedial; m-, medial; mdm-, medial dorsomedial; pm, posteromedial; rd-, rostrodorsal; rl-, rostrolateral; rm-, rostromedial; vm-, ventromedial; vl-, ventrolateral. The figure and legend were originally published in Alexander et al 8 and are used here with permission. 


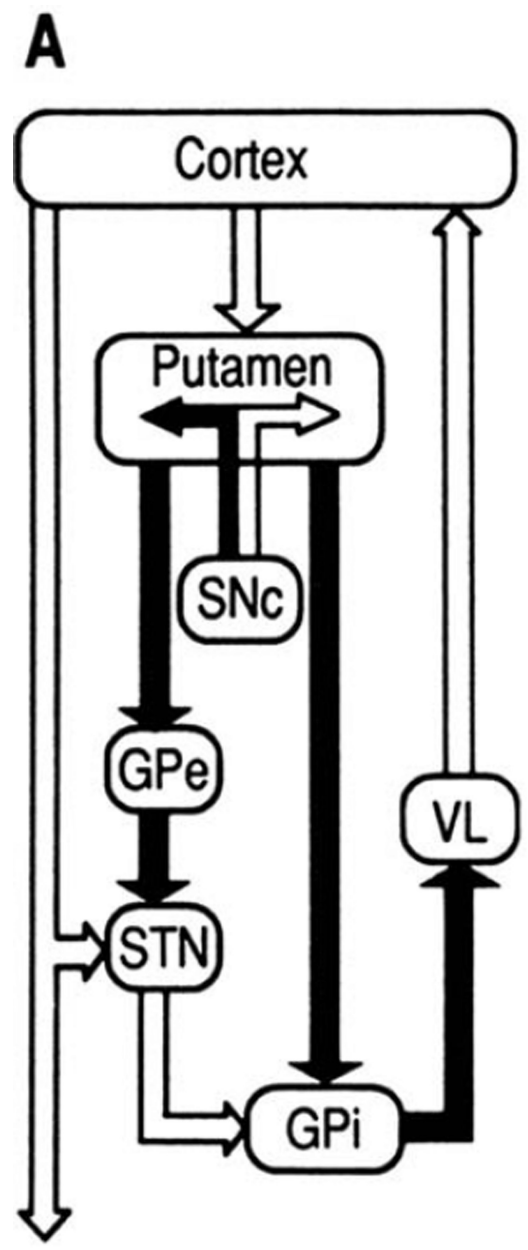

B

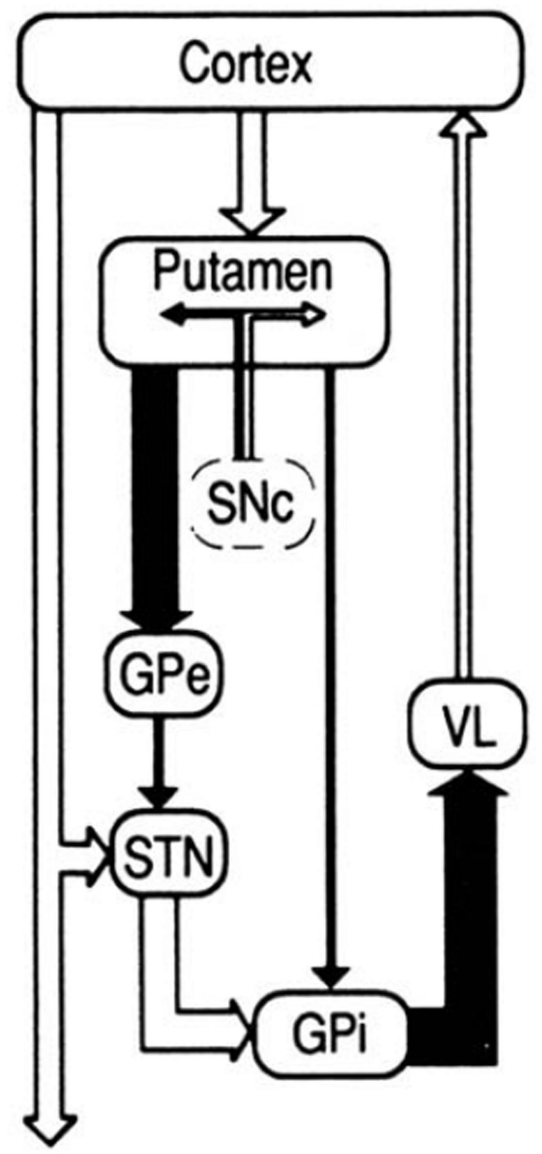

C

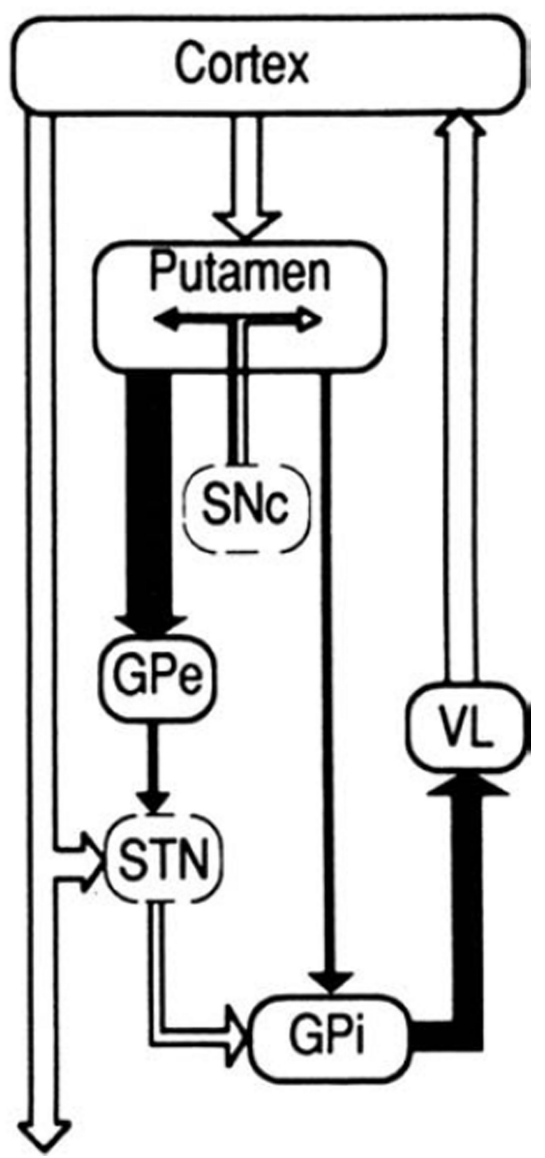

FIG. 2.

Functional connectivity within the basal ganglia - thalamocortical circuits under normal and parkinsonian conditions, as proposed by Bergman et al (1990) ${ }^{20}$ A: Normal (open arrows, excitatory collections; filled arrows, inhibitory collections. SNc, substantia nigra pars compacta; VL, ventrolateral nucleus of the thalamus). The putamen (the "input" stage of the circuit) is connected with GPi (the "output" stage) by direct and indirect projections (via GPe and the STN). The postulated differential effects of dopamine on the 2 striatal systems are indicated schematically. B: MPTP-induced parkinsonism. After treatment with MPTP, the SNc was damaged. Resulting changes in the overall activity in individual projection systems are indicated as changes in the width of arrows. Inactivation of the nigroputamenal projection increased GPi activity, secondary to an increase in excitatory drive from the STN and a decrease in direct inhibitory input from the striatum. The resulting overinhibition of thalamocortical circuits may account for some of the parkinsonian motor signs. C: Effect of STN lesions in parkinsonism. Inactivation of the STN reduced GPi output to the thalamus toward more normal levels, thus reducing parkinsonian motor signs. The figure and legend were originally published in Bergman et al20 and are used here with permission. 
Normal

$\mathrm{GPe}$

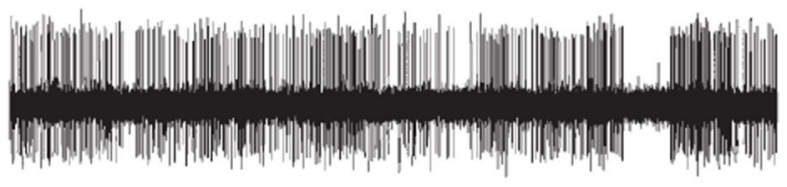

STN

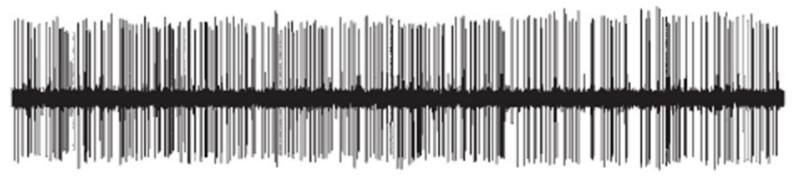

GPi

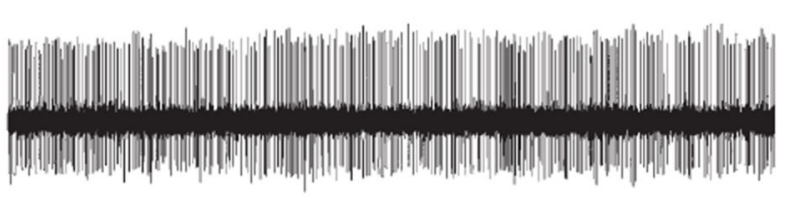

Parkinsonism

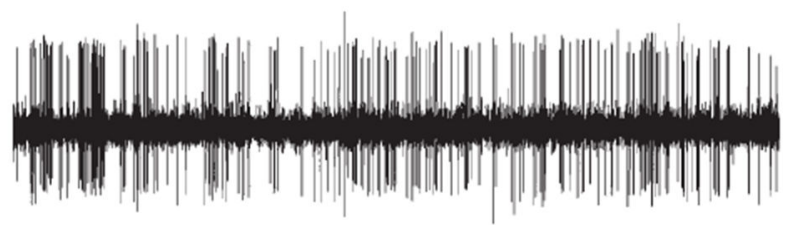

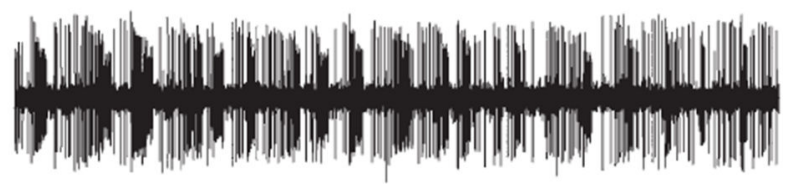

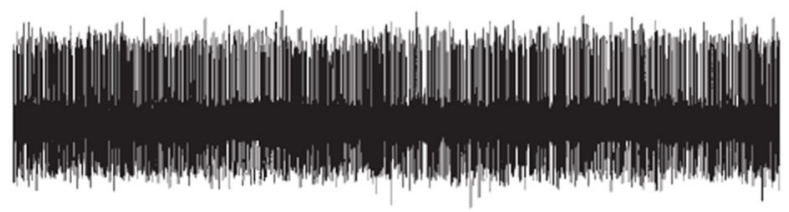

FIG. 3.

Changes in the activity of single cells in GPe, STN, or GPi of MPTP-treated monkeys. Shown are example recordings of separate neurons, recorded with standard methods for extracellular electrophysiologic recording in normal and parkinsonian animals. Each data segment is 5 seconds in duration. This figure and the legend were originally published in Galvan and Wichmann115 and are used here with permission. 


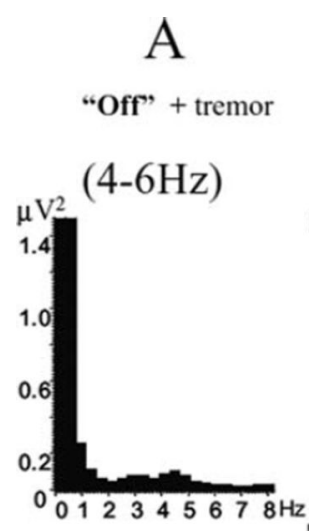

B
"Off"
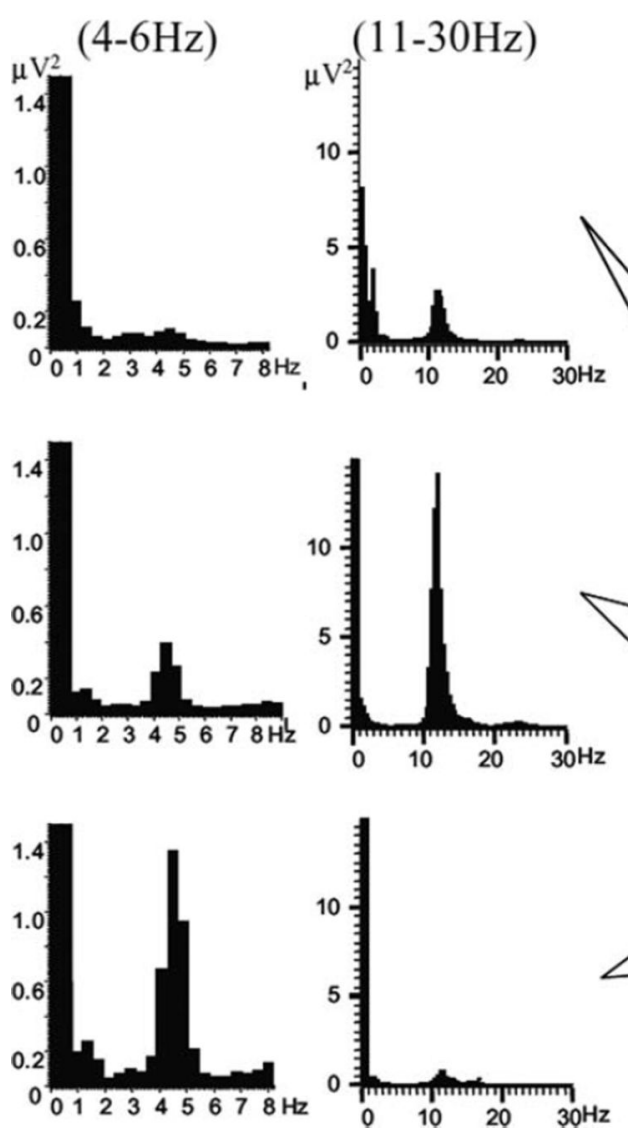

FIG. 4.

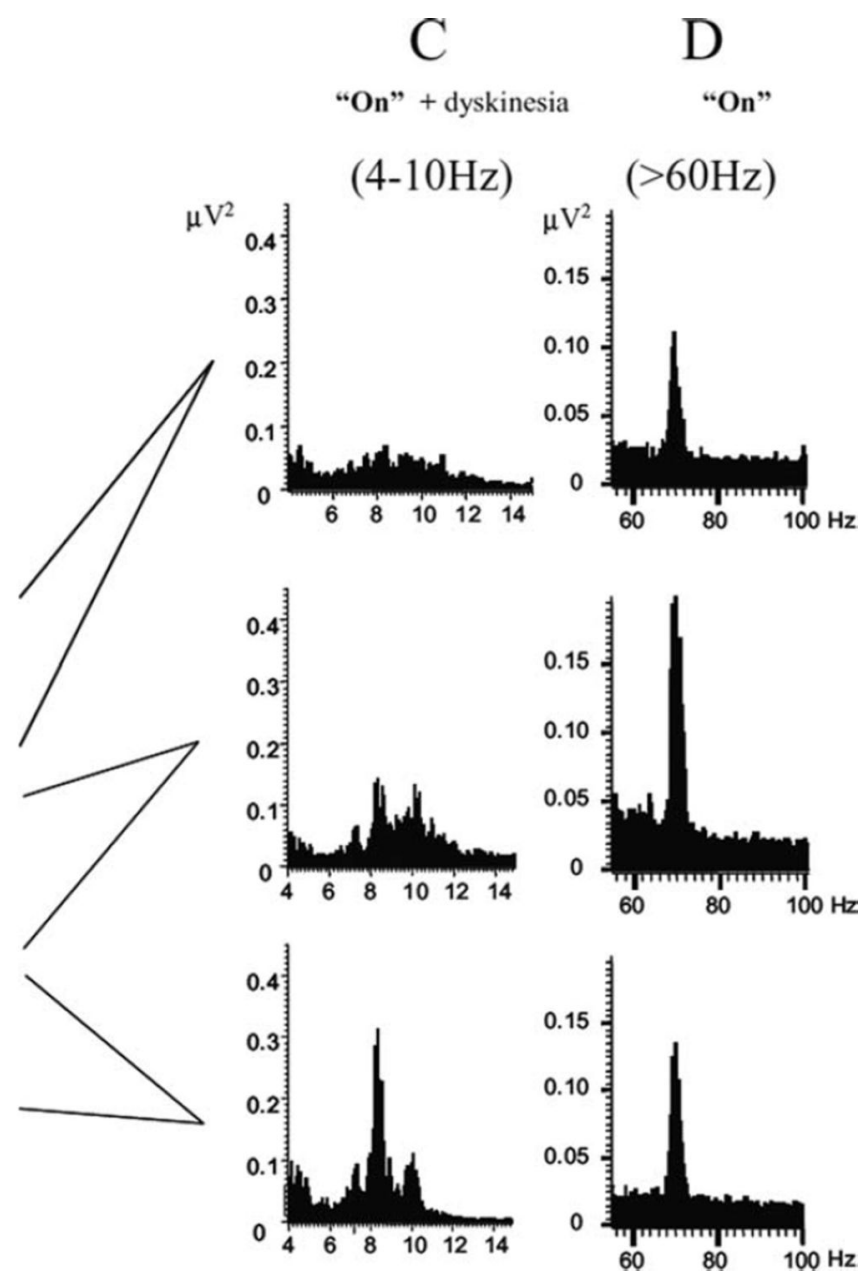

Oscillatory local field potential activity in the subthalamic nucleus. Shown is the evolution of the LFP autospectra throughout the "off-on" cycle and the predominant site of recording with respect to 3 bipolar contacts in the STN. In the "off" motor state (left) in a patient with tremor (A), there is a predominant peak at around $5 \mathrm{~Hz}$, whereas in a patient without tremor (B), there is only a peak at around $11-12 \mathrm{~Hz}$ that is maximal at the second-most dorsal STN contact. In the "on" 1 dyskinesias motor state (right), the same patient shown in $\mathbf{B}$ exhibited a $4-$ to $10-\mathrm{Hz}$ peak predominantly at the ventral recording site (C) and a $60-$ to $80-\mathrm{Hz}$ peak at all 3 sites, although the middle contact predominated (D). This figure and the legend were originally published in Alonso-Frech et $\mathrm{al}^{90}$ and are used here with permission. 